\title{
Hereditary dentin defect
}

INSERM

\section{Source}

INSERM. (1999). Orphanet: an online rare disease and orphan drug data base. Hereditary dentin defect. ORPHA:167759

The hereditary dentin disorders, dentinogenesis imperfecta (DGI) and dentin dysplasia (DD), comprise a group of conditions characterized by abnormal dentin structure affecting either the primary or both the primary and secondary dentitions. 